\title{
The Extent of Applying the Diagnostic Evaluation by the First Grade Teachers in Teaching Copied Dictation in the Schools of Ma'an
}

\author{
Mohammed Abd Al-kareem Nafa' ${ }^{1}$ \\ ${ }^{1}$ Faculty of Educational Sciences, Al-Hussein Bin Talal University, Jordan \\ Correspondence: Mohammed Abd Al-kareem Nafa'a, Faculty of Educational Sciences, Al-Hussein Bin Talal \\ University, P. O. Box: (20) Ma’an, Jordan. Tel: 962-079-502-8846. E-mail: emt.lady22@yahoo.com
}

Received: July 29, 2014

doi:10.5539/hes.v4n5p89
Accepted: September 2, $2014 \quad$ Online Published: September 20, 2014

URL: http://dx.doi.org/10.5539/hes.v4n5p89

\begin{abstract}
This study examined the extent of the teachers' of the first grade applying to the components of diagnostic evaluation in teaching dictation in Ma'an, and the answer two question this study, the researcher chose a sample consisting of (60) teachers (females) who teach this grade, holders of B.A degree. The researcher attended classes with these teachers and detected the notes by the remarks' card, and spotted remarks by Card note that by The Reliability and The Validity was 0,84 Data were statistically analyzed and the study concluded that the teachers who teach dictation apply the components of the diagnostic evaluation, and also showed that there was no statistically significant differences due to the variable of the four educational directorates in Ma'an, which show that the teachers apply the contents of the training courses that are conducted by the Ministry of Education to qualify them for teaching. The researcher proposed a set of recommendations mentioned at the end of the study.
\end{abstract}

Keywords: diagnostic evaluation, dictation, female teachers, first grade

\section{Theoretical Background}

The eighties decade in Jordan witnesses an educational development that included all sectors of education, to cope with the development in technology, that made the world a small village.

Since the school is the minaret through which change begins, it has received more interest to raise the capacities of the educators. In this context, development included laws and regulations, curriculum, teachers, management, labs, teaching methodologies, methods and evaluation (Al-Farhan, 1994).

Typically, tests have been the tool based on which a decision is taken to move to the next stage of education to promote the students from one class to another.

In addition, the teaching process through which instruction takes place is seen as a step-by-step process in terms of difficulty, with a non-homogeneous group of individuals who receive information. This is noted mostly in teaching dictation to the primary stage students, where learners are judged as having knowledge through exams that are conducted from one time to another, without considering the reasons that results in the progress of some students, to enhance them, and to treat the weakness points (Al-Kilani,1993).

On the other hand, evaluation is seen as the only resource to issue decisions on the progress of the students, without employing the results to treat the weaknesses, and to put short and long term plans to achieve the objectives of these plans, not to forget the importance of improving the outputs of instruction that reflect on the society and its progress to become one of the developed countries (both scientifically and technically).

Despite the various critics to the methods of teaching dictation of different types (the copies, seen, listened and elective), which focus on presenting it through steps that help the learners understand its basis and rules, teachers still exaggerate in giving the copies dictation by the method of listening and elective methods, which are appropriate only for the higher grades, but teachers do not consider the methods and means that help facilitate conveying knowledge to the learners, since it is - from their perspective - a waste of time and on the expense of other knowledge (Al-Kholi, 2000).

Based on the above, this purpose of evaluation is to decide the passing and failing students in the learning process and which can be used as a tool to insure that the school performs the tasks assigned to it, and applies the 
modern strategies in instruction, to graduate learners who are equipped with science and knowledge.

Despite the importance of dictation in the writing composition, but the methods of teaching this subject have not yet reached wit the learner to draw and write the words correctly, and did not consider the picture and noting of the letters, as well as employing more than one sense for learning. In fact, dictation is a written photography of the spoken works that allow the reader to re-speak or write them in accordance with the picture of speaking those words (Al-Bajjeh, 1994).

In this regard, scholars previously have examined the rules of dictation, but they did not agree on other rules; opinions and perspectives varies, which was negatively reflected on the students while writing, with weakness in writing in Arabic, which largely vary from the live languages, because its words are subject to fixed rules while dictation, and should be taken into account when expressing the needs, attitudes and desires. Accordingly, any increase or decrease in the rules of dictation will affect the intended meaning (Margaret \& Mary, 1991)

Consequently, Arabic is complete full component without separation of any part; syntax and semantics are means to control writing without increase or decrease in the meaning; dictation is an important means for writing; a mistake in dictation will distort writing, makes it difficult to understand a sentence and changes its meaning.

Based on the above, it can be noted that the purpose of dictation limited on these close borders that some people can understand, but it is a means for various colors of language activity, an exercise on various skills, to gain good habits in writing, reading and general culture.

In addition, it is one of the important language arts, which is divided into types that should be consistent with the age levels of the learners; what is good for the secondary stage is not fit for the primary grades. Among the most important types of dictation are:

The copied dictation: which means that students copy from the book, board or any other means that a teacher deems appropriate, after reading, understanding, with the oral spelling of some of its words. This kind of dictation is appropriate for the beginner students (the first grade), since it is consistent with their capacities and to develop their knowledge (Al-Ja'afreh, 2011)

1) The copied dictation: and means to convey the students piece of the book or the board .

2) The seen dictation: this kind of dictation is taught by presenting a piece to the students, then it is read correctly, explained in full to be understood by the students, with oral pronunciation of some words, written on the board or covered by a curtain, then cleaned without trace, but can been seen by the students if they concentrate on it. Then it is dictated word by word, then hidden. The teacher asks the students to write it. This kind of dictation is appropriate for the primary grades especially the second and third grades.

These two kinds of dictation are similar in teaching, but both are different in implementation only; in the first kind (the copied), students copy a passage from the book or the means used by the teachers, whereas in the second kind (the seen) a student can see it when needed to achieve the planned objectives (Al Hashimi, 2009)

There are other kinds of dictation including the listening, dictation for test, and self- dictation. These kinds are appropriate for the higher grades. Since this study is concerned with the lower classes and in the first grade specifically, then we will not discuss these kinds in more details, and will be left for other researchers to examine their difficulties.

Due to the importance of dictation, scholars consider it as a keystone for functional and creative writing and an important means for correct reading as well as writing in its various forms. In addition, it contributes in instilling the pieces of information as it focuses on the listening, speaking, visual and aesthetic remembering, but it in our schools, it is still by sponge teaching without developing the means of knowledge that help to master writing and employ it life situations (Al- Safasfeh, 2004)

Furthermore, dictation will not produce its fruit if not accompanied by formative evaluation (the continuous) which corrects mistakes first-by-first, as it represents along with other kinds of dictation main basis to explore the products and outputs of the learning-teaching process.

Moreover, research and modern studies were concerned with evaluation, since it is a main aspect of curriculum that was defined by Thorndike as: A Description of a thing/object that was accepted or appropriate in accordance with levels and criteria that proposed in advance (Thorndike, 1961).

From the above, we conclude that evaluation is based on various processes with the help of data and information to enable us issue a judgment that improves the results of the learning process. 
Psychology scientists stated that there are various kinds of evaluation, and all of them are used when teaching dictation of all kinds. Those kinds complement each other, and all of them represent a set of objectives that pour for the interest of learners who are the theme of the learning- teaching process, mostly the diagnostic evaluation.

In this context, the diagnostic evaluation started with a set of measures that aim at measuring the largest number of capacities; dictation contains a series of capacities which a student is supposed to develop, and the most important purposes is to diagnose the defect first- by-first, to provide the suitable treatment.

The Scottish council defined it as: one of the evaluation aspects that represent a part of the learning process, with the aim to examine the learners learning to uncover their performance, test their capacities and needs based on their academic achievements, to achieve the educational objectives, discover their thinking methods in order to enable the female teachers choose the best methods of teaching the copies dictation.

Moreover, diagnosis is one of the methods that are based on the principle of gathering information about the learners, used as a feedback during the planning for future learning, based on the individualized learning, allows each student to learn and achieve him/her self, and satisfies the utmost needs, and is a part of the teaching process (a successful teacher practices it in teaching and instruction prior and after the class situation). This kind of evaluation cares about the learner or the homogenous group of learners in terms of their performance, and is based on a set of principles.

\subsection{Problem of the Study}

The parents complain that their children are weak in writing; they memorize the copied dictation by heart, and without effect. This contradicts the objective of teaching dictation that is taught through steps to keep its effect with the learners. However, we did not notice that skill with the teachers of Arabic language and specifically in dictation; they teach it in a traditional way that kills creativity, with negative effects on the results, not to forget the need to take the suitable decision to remedy the difficulties of correct writing.

On the other hand, it could be said that the teachers who teach the copied dictation do not apply the teaching strategies as they receiving during the training to implement such kind of dictation, including the strategies of diagnosis evaluation, that play a significant role in treating the weaknesses .

Lack of studies that examined the southern governorates and Ma'an in specific in terms of the copied dictation in light of the diagnostic evaluation.

\subsection{Importance of the Study}

Dictation has a significance and high purpose. It is possible to apply dictation through various kinds of linguistic activities, to provide the learners with good habits in writing and organization, affecting written expression and summarization, general culture, and good hand-writing, not to forget that it affects various skills and good habits.

Due to the repeated complaints about the students' weakness in dictation, this problem became a source of concern among educational specialists, families and the whole community. Consequently, this study was implemented on the first primary grade, due to the importance of this grade in the educational level. In addition, this study comes as a response to the calls that invited to improve the students' level in dictation, since it is the key-bone of Arabic, not to forget the need to diagnose the extent of applying the correct strategies to teach dictation, including the diagnosis evaluation method that defines the defect prior and after the lesson, and based on the results, the suitable treatment will be provided.

In this regard, it is worth mentioning that Arabic is facing a clear shortage in such research, especially in teaching the copies dictation. As a result, the importance of the study is represented in:

1) Develop the methods of teaching dictation, taking the necessary actions to enhance the students' capacity in copied dictation and to improve the teachers' abilities.

2) Inform the decision makers about the importance of diagnosis evaluation in teaching the copied dictation and to put directories showing the steps of teaching this subject.

In this essence, we hope this study will be a start for other studies to treat the weakness of the students of the primary stage and other states due to its importance.

3) To generalize teaching by the diagnosis evaluation method on all subjects, while following the teaching steps that treat weaknesses, first-by- first.

\subsection{Definition of the Terms}

Dictation in language: The correct drawing of words (Safasfeh, 2004). 
Dictation as a term: The correct writing of words, which shall be drawn correctly through training and organized practice, with correct view of words and their pictures, noting their letters correctly and using more than one sense while writing the words (Jabir, 2002).

Copied dictation in language: $\mathrm{He} / \mathrm{she}$ copies the thing/object- changed it from one place to another and - copied the book: wrote it and copied the news with the language of the speaker (Alfair Zabadi, 1994).

Dictation as a term: It is called the copied dictation; the students copied the passage from the book or black board or a card after reading, understanding and spelling its words. This kind of dictation is suitable for the beginning students (Al Hashimi, 2009).

Diagnosis in language: Assigned and distinguished it from others. It is said: he diagnosis the disease, means defined the problem (Ibrahim, 1989).

Diagnosis as a term: To define the defect and its reasons, with the provision of the suitable treatment through accurate study and follow up.

Evaluation in language: From the verb evaluated, and corrected the crooked, meaning amended it. It is also said: he evaluated the goods, meaning its price and value, and assigned its value or price (Manzour, Al-Ifriqi 1968).

Evaluation as a term: The evaluation that complements the methods a teacher uses during the class situation to achieve the projected objectives with the students (Ya'qoub, 1970).

The card in language: A small piece of paper that contains information about a person: with an official consent. The family card is a book that contains the family name (the plural is: cards) (Badawi, 1980).

Note card: A card with a specific length and width, that contains the remarks to be detected from a targeted educational situation.

Female teachers: Those who are assigned to teacher the primary stage students, including the first grade (the target of this study). Teaching in this stage is mix, free and compulsory.

The first primary grade: The class when the learning process begins, which is one of the lower primary grades. Teaching in this stage is mix, free and compulsory.

Ma'an governorate: The Hashemite Kingdom of Jordan consists of twelve governorates, one of them is Ma'an, located in the southern part of Jordan, with a number of districts (the Qasaba, the southern Badia, Petra and Shobak). Ma'an is $300 \mathrm{KM}$ to the south of Amman the capital.

Our Arabic language: A book that is designed to the lower primary stage students, that is consistent with their abilities and needs. The book is written with an interesting and easy method, which focus on the sensed but not the abstract.

\subsection{Questions of the Study}

Researcher wants in this study to answer the following two questions:

- What is the extent of the teachers' of the first grade applying to the components of diagnostic evaluation in teaching dictation?

- Are there any differences in applying the component of the diagnostic method among the educational directorates, the sample of the study (Qasabat Ma'an, Petra, Shobak and the southern Badia)?

\subsection{Limitations of the Study}

The researcher limited the study with:

- The first grade students.

- The five components of the diagnosis evaluation (appendix A).

- The book (Our Arabic language) for the first grade.

- Ma'an governorate and the affiliated districts/counties, namely: (Al- Qasaba, Badia district, Shobak and Petra).

- The study was applied during the second semester of the academic year (2012/2013).

\section{Previous Studies}

The strategy of diagnosis evaluation is new in education in the Arab world, and is applied on the primary stage students in collaboration with (O.D.A) 
This is the reason for the lack of Arabic studies in this field. However, there are plenty of foreign studies in this field.

Among the most important studies, the one conducted by Hassan (2000) which examined the effectiveness of teaching by using the diagnosis evaluation of Arabic language in the primary stage, through comparing the achievement level for the students who study by this method, compared with those who study by traditional methods. In specific, the researcher attempted to answer the following question:

- Does the use of teaching by diagnosis evaluation achieve educational outputs better than using other methods in teaching Arabic?

Data was treated based on the assumptions of the questions using (SPSS) to test the hypothesis, in addition to using the descriptive statistics. The study concluded with the following results:

- The students' achievement level who learned with the traditional methods was better than the level of those students who learned with the diagnosis evaluation.

- There was an effect for the teaching method, student gender, teachers' experiences and qualifications on the level of student achievement.

- There were no significant statistical differences for gender, qualifications and job title on the degrees of teacher practices and their perspectives towards the diagnosis evaluation method.

The results of tests or questionnaires did not show any differences between the means of student achievement due to the variable of experience (Hasan, 2000)

Marion, 1997, conducted a study (within the context of her report about the consultation visits to Jordan in November, 1997), where she reviewed the experience of teaching by the diagnosis evaluation method in Jordan for Arabic and mathematics.

The study intended to examine the success of the experiment and its level of development. The researcher made various visits and participated in the training circles of two tests for the sixth grade, which included Arabic and maths. The study included 18 schools, six schools for males and 12 for females (number of students: 1061). The variables of the study were: subject, teaching material, gender, participation in the program, directorates, schools and classes (Devire, 1997)

The researcher prepared two questionnaires to know the perspectives of the participants in the diagnosis evaluation program regarding the class situation, role and attitudes of the teachers towards the subjects they teach using this method.

The researcher concluded that there is an interest with the student level, with a consideration to the individual differences, variation in the evaluation methods used by the teachers, with the common use of open-ended questions that are designed to test various capacities.

In addition, the results of the study showed an increase in the class interaction and more attention to the weak students. Moreover, teacher were alert to discover the weakness points, with more interest to develop performance records, student achievement as well as cooperation with the parents to solve the problems facing the students.

Mohammed (2003) conducted a study that examined the effect of teaching the grammar of Arabic, using the diagnosis evaluation, compared with the traditional method, on learning the grammar by the ninth grade students in the schools of Qasabat Ma'an.

The researcher used the uni-analysis method in the statistical treatments to answer the questions of the study, which was tested at (0.05). the results of the study were as follows:

- The average of the students' marks, who learned with the diagnosis method $(20.72 \%)$ was higher than those students who learned with traditional method (18.56\%).

The results of the statistical analysis showed significant differences between the means of both groups at $(0.05)$ $(\mathrm{F}=2.38)$. This can be attributed to the treatment method, for the benefit of those students who had a means of (20.72) (Tarawneh, 2003)

Sa'eed (1983) conducted a study on the secondary school students in the Kingdom of Saudi Arabi. The researcher divided the sample into six groups; three were exposed to the diagnostic tests and three groups did not receive any tests. This was achieved through the teaching method to overcome the educational obstacles that emerged during the diagnostic tests. The researcher distributed those students based on the tests (three levels) one of them received the treatment by the teacher, the other received direct treatment and the third did not 
receive any treatment.

The study showed significant differences for the diagnostic tests in treating weaknesses in the academic achievement of the secondary school students.

In 1995, Ismail Mokhtar conducted a study that aimed at developing the diagnostic tests for the various concepts and their effect on the ability to solve mathematic problems in Malaysia. The researcher used the classification of the test objectives in accordance with a relative relationship, and used another classification to build similar items for each objective.

The diagnostic items included the linguistic aspect, strategic and logarithm planning. 1255 students participated in the test which achieved high validity. The test examined four themes: external validity, the aspects that form validity and the aspects relating to the subject.

The results showed a relationship between the objectives and items through the standardization of the test. The study provides a new correction and development for the plan to make the validity of the tests. However, this test was specifically designed when the class size is large, while teachers have no opportunity to provide the diagnostic evaluation which consider the individual differences among the students (Saud, 1983).

From the above studies, the researcher concluded with the following:

- Most of the studies which the researcher found were foreign, old and relate to the scientific knowledge, but not relating to Arabic language at all.

- Most of the Arabic studies were conducted on branches of Arabic language, but did not deal with the copied dictation and the first primary grade in specific.

- The studies focused on the importance of the diagnostic evaluation in teaching, except the study conducted by Hassan (2000).

- The studies conducted in Jordan were implemented on the higher primary and secondary grades, but not on the primary stage that include the first grade.

- Through this method, it is possible to decide the defect first-by first, and then the suitable treatment will be offered, which is reflected on all students. This was noted through those studies.

Consequently, it could be said that this study is important for instruction, since it concentrates on the diagnostic evaluation method and its main components. In addition, this study is considered one of the important studies, since it is the first in the field of copied dictation and is concerned with a sample of students who have their special specifications.

\section{Method and Procedures}

Among the most important procedures to apply the study were:

\subsection{Population}

The population of the study consisted of all teachers of the first grade who teach Arabic $(\mathrm{N}=100)$ in Ma'an Educational Directorate (Al- Qasaba, Badia district, Shobak and Petra) during the academic year (2012/2013).

\subsection{Sample of the Study}

The sample of the study consisted of (60) female teachers, chosen with the were selected random method from the directorates Ma'an governorate (Al- Qasaba: 15, Badia district: 15, Shobak: 15 and Petra:15)

\subsection{Instruments of the Study}

- Addressing the educational directorates to allow the researcher and the supervisors of the (practical education)* to visit their school and attend class situations while teaching the first grade students.

- After having the approval to visit the schools, the researcher coordinated with the sample teachers to attend class situation where copied dictation is taught to the first grade students.

- Detecting these situations using the remark cards that contain specific points of the main principles of the diagnosis evaluation, mostly:

1) Planning for the class situation that will be implemented.

2) Learning and teaching methods.

3) Detecting the results of the students after implementing the class situation.

4) Distribute the results to the concerned parties/ stakeholders. 


\subsection{Mechanism for Implementing a Tool Study}

First: model reading by the teacher, in such a correct and good way.

Second: follow- reading by the good students.

Third: giving/explaining the meaning of the difficult words contained in the dictation piece.

Forth: explaining the dictation piece to the students.

Fifth: train the students to write dictation on the blackboard or any other means that is appropriate for this age group. This aims at the diagnosis of the weakness and strength points, which can be an activity as follows:

- In light of the diagnosis of weakness and strengths, the teacher divides students into two groups, one who did not face dictation difficulties, and the second are those who are weak students.

- The one who had no difficulty in activity (1) a dictation to learn, with colors that are different from the other letters of the word.

A supervisor: a technical expert whose main task is to help develop the teachers professionally and solve the educational problems that face teachers, in addition to the provision of the technical services to improve teaching methods and guide the educational process appropriately.

- The weak students will receive a remedial activity to help them overcome the weakness, while training all students on the blackboard (activity 1), as follows:

a. Connect the points with each other to form one word or a specific letter.

b. Connect the slashes together to form one word or a specific letter.

c. The teacher holds the students' hand and help her do the copied dictation.

d. The teacher asks the students to form specific letters or syllables and color them with specific colors.

e. The teacher asks the students to spell the letters and connect them together, until treating the weakness.

f. After treating the difficulties, students are given activity (2) which was implemented by those students who did not face difficulties. During this tasks, the teacher will inspect the work of the groups, and tries to diagnosis the difficulties that may arise while implementing activity (2), and works to treat the weaknesses.

g. The teacher provides the new knowledge with an interesting method, with a focus on the expected difficulties, so that the students will avoid them.

h. The teacher will present activity (3) for the two groups to treat a specific dictation issue, and asks the students who faced difficulties in activity (1) to form one group and provides them with a remedial activity to help them implement this activity. The teacher continues to provide the prior knowledge before implementing the copied dictation until insuring that those students mastered the targeted dictation.

Sixth: the passage will be read for the students and they will copy it from a book or another means, while giving the necessary instruction to help the students and develop their attitudes towards specific issues such as organization, cleanness, self-dependence, and they have to leave the word which they do not know, and write it until re-reading the text again.

Seventh: reading the passage faster than the first, so that the students can write the part which they could not write from the first time.

Eighth: a second reading for the good students, to insure not missing any words.

Ninth: the teacher corrects the notebooks for every student separately, and decides the mistakes committed by each student

Tenth: after deciding the mistakes committed by each student, the common mistakes are decided, and they receive training on the blackboard or any other appropriate means.

In sum, if the teacher practiced this method, then she will master teaching this subject to this group, spend full day with them and achieve the required objectives.

In addition, the teacher shall repeat this method to enhance information in the students' minds, and if they master reading and writing, then they can rely on themselves to learn. 


\subsection{The Mechanism of Evaluating the Tool Study}

- Visiting the targeted sample by the researcher and supervisors, twice.

- Using the remark card to detect the class situations (as shown in the card 5-1) to examine the level of teachers' application for the components of the diagnosis evaluation as follows: (Too big $=5$; $b i g=4$; medium: 3; little:2, very little: 1) (appendix 1)

- To analyze the situations that were detected (statistically) to answer the questions of the study).

\subsection{The Reliability Tool}

The researcher View tool on a group of arbitrators from Mutah University and the University of AlHussein and some of the supervisors and some basic first-grade female teachers for the Study of Arabic language Until become its image as in Appendix (1).

The mark 3 considered mark limit an agreement all arbitrators to those applies components of the evaluation diagnostic during the implementation of dictation.

\subsection{The Validity of the Tool}

The researcher selection (10) female teachers studying first grade from outside the sample And applied them tool of study then re-applied after two weeks and calculated the Validity 0,84 and this result is acceptable for this study

\section{Statistics Study}

The researcher used the survey method to identify the extent to which the application female 1 teachers the first grade of the components of diagnostic evaluation during teaching dictation copied and the approach descriptive to find out about the application of the different components of the diagnostic evaluation depending on the Education Directorates .

The researcher visited the study sample, which represent $60 \%$ of the study population twice by the researcher and one of the supervisors practical education at the University of Al-Hussein Bin Talal monitored and analyzed the data statistically

\subsection{Variables of the Study Are}

-Independent variable:

Directorates of Education, four :

Educational Qasabat Ma'an

Educational Shobak

Educational Badia

Educational Petra

-The dependent variable: the application components diagnostic evaluation during teaching dictation copied

\section{Results and Discussion}

\subsection{The Result}

This study examined the extent of the teachers of the first primary grades' application for the diagnostic evaluation method in teaching the copied dictation. Specifically, the study attempted to answer the following two questions:

1- What is the extent of the teachers' of the first grade applying to the components of diagnostic evaluation in teaching dictation?

2- Are there any differences in applying the component of the diagnostic method among the educational directorates, the sample of the study (Qasabat Ma'an, Petra, Shobak and the southern Badia)?

In order to answer those two questions, the researcher attended class lessons with the sample of the study (the teachers), detected the remarks that were written on the remark card, and the necessary statistical processes were implemented to answer the questions. The results were as follows: 
Table 1. Means and standard deviation for the teacher responses at the critical mark (3)

\begin{tabular}{llll}
\hline Dimensions & Number & Means & S. deviation \\
\hline Planning & & 3,9667 & .18473 \\
Learning & & 3,8600 & .34797 \\
Result detection & 60 & 3,4767 & .38986 \\
Result distribution & & 3.2867 & .44397 \\
Evaluation & 2.7967 & .31781 \\
Total & 3.4773 & .15896 \\
\hline
\end{tabular}

To examine the differences between the responses of the teachers at the benchmark (3), T-test was implemented for one sample.

Table 2. T-test results for one sample on the benchmark (3) which represent the means

\begin{tabular}{llll}
\hline Dimension & t- value & Freedom degree & Significance level \\
\hline Planning & 40.534 & & .000 \\
Learning & 59 & 19.144 & .000 \\
Result detection & & 9.471 & .000 \\
Result distribution & & 5.002 & .000 \\
Evaluation & & -4.956 & .000 \\
Total & & 23.260 & .000 \\
\hline
\end{tabular}

From the above table, it is noted that T-values for each dimension, and the total measurement instrument were statistically significant. Accordingly, it could be said that the teachers' application (who teach the first primary grade) for the five components of the diagnostic evaluation while teaching the copied dictation was close, since they received training on these components prior to joining the teaching profession, as they were prepared and learned the correct teaching methods.

Table 3 shows the extent of applying the components of the diagnostic evaluation method by the teachers of the first primary grade, as per the directorates of education. Means and standard deviations were calculated (table 3).

Table 3. Descriptive data as per the variables of the educational directorates and the sample of the study

\begin{tabular}{|c|c|c|c|c|c|}
\hline \multirow[b]{2}{*}{$\begin{array}{l}\text { Method } \\
\text { evaluation }\end{array}$} & \multirow[b]{2}{*}{ of } & \multirow[b]{2}{*}{ Variables of the study } & \multirow{2}{*}{$\begin{array}{l}\mathrm{N} \\
\text { Number }\end{array}$} & \multirow{2}{*}{$\begin{array}{l}\text { Mean } \\
\text { Means }\end{array}$} & \multirow{2}{*}{$\begin{array}{l}\text { S. Deviation } \\
\text { Standard Deviation }\end{array}$} \\
\hline & & & & & \\
\hline \multirow[t]{5}{*}{ Planning } & & Qasabat Ma'an & 14 & 3.9467 & .17674 \\
\hline & & Shobak & 15 & 3.9467 & .21996 \\
\hline & & Badia & 15 & 3.9467 & .14075 \\
\hline & & Petra & 15 & 4.0267 & .19809 \\
\hline & & Total & 60 & 3.9667 & .18473 \\
\hline \multirow[t]{5}{*}{ Learning } & & Qasabat Ma'an & 15 & 3.7600 & .28486 \\
\hline & & Shobak & 15 & 3.9200 & .41266 \\
\hline & & Badia & 15 & 3.8933 & .31045 \\
\hline & & Petra & 15 & 3.8667 & .38297 \\
\hline & & Total & 60 & 3.4267 & .24919 \\
\hline
\end{tabular}




\begin{tabular}{lllll}
\hline Result detection & Qasabat Ma'an & 15 & 3.4267 & .24919 \\
& Shobak & 15 & 3.5067 & .35349 \\
& Badia & 15 & 3.4667 & .39036 \\
& Petra & 15 & 3.5067 & .54441 \\
& Total & 60 & 3.4767 & .38986 \\
Result distribution & Qasabat Ma'an & 15 & 3.3067 & .53381 \\
& Shobak & 15 & 3.2267 & .45272 \\
& Badia & 15 & 3.3467 & .46884 \\
& Petra & 15 & 3.2667 & .33523 \\
& Total & 60 & 3.2867 & .44397 \\
\hline
\end{tabular}

From the above table, it is noted that there are clear differences between the means of the responses of the participants according to the directorate. To examine the significance of these differences, the uni-variance was analyzed. Here is a summary of this analysis:

Table 4. Results of the uni-variance analysis according to the educational directorates as per the components of the diagnostic evaluation

\begin{tabular}{|c|c|c|c|c|c|c|c|}
\hline $\begin{array}{l}\text { Components of } \\
\text { the diagnostic } \\
\text { evaluation }\end{array}$ & $\begin{array}{l}\text { Resource } \\
\text { variance }\end{array}$ & of & $\begin{array}{l}\text { Total of } \\
\text { squares }\end{array}$ & $\begin{array}{l}\text { Freedom } \\
\text { degree }\end{array}$ & $\begin{array}{l}\text { Means of } \\
\text { squares }\end{array}$ & $\mathrm{F}$ values & $\begin{array}{l}\text { Significance } \\
\text { level }\end{array}$ \\
\hline \multirow[t]{2}{*}{ Planning } & $\begin{array}{l}\text { Between } \\
\text { squares }\end{array}$ & the & .072 & 3 & .024 & \multirow[t]{3}{*}{.692} & \multirow[t]{3}{*}{.561} \\
\hline & $\begin{array}{l}\text { Within } \\
\text { squares }\end{array}$ & the & 1.941 & 56 & .035 & & \\
\hline Total & & & 2.013 & 59 & & & \\
\hline \multirow[t]{3}{*}{ Learning } & $\begin{array}{l}\text { Between } \\
\text { groups }\end{array}$ & the & .221 & 3 & .074 & \multirow[t]{3}{*}{.597} & \multirow[t]{3}{*}{.620} \\
\hline & $\begin{array}{l}\text { Within } \\
\text { groups }\end{array}$ & the & 6.923 & 56 & .124 & & \\
\hline & Total & & 7.144 & 59 & & & \\
\hline \multirow[t]{3}{*}{ Result detection } & $\begin{array}{l}\text { Between } \\
\text { groups }\end{array}$ & the & .066 & 3 & .022 & \multirow[t]{3}{*}{.138} & \multirow[t]{3}{*}{.937} \\
\hline & $\begin{array}{l}\text { Within } \\
\text { groups }\end{array}$ & the & 8.901 & 56 & .159 & & \\
\hline & Total & & 8.967 & 59 & & & \\
\hline \multirow[t]{3}{*}{$\begin{array}{l}\text { Result } \\
\text { distribution }\end{array}$} & $\begin{array}{l}\text { Between } \\
\text { groups }\end{array}$ & the & .120 & 3 & .040 & \multirow[t]{3}{*}{.195} & \multirow[t]{3}{*}{.900} \\
\hline & $\begin{array}{l}\text { Within } \\
\text { groups }\end{array}$ & the & 11.509 & 56 & .206 & & \\
\hline & Total & & 11,629 & 59 & & & \\
\hline \multirow[t]{3}{*}{ Evaluation } & $\begin{array}{l}\text { Between } \\
\text { groups }\end{array}$ & the & .146 & 3 & .049 & \multirow[t]{3}{*}{.460} & \multirow[t]{3}{*}{.705} \\
\hline & $\begin{array}{l}\text { Within } \\
\text { groups }\end{array}$ & the & 5.813 & 56 & .104 & & \\
\hline & Total & & 5.959 & 59 & & & \\
\hline
\end{tabular}


From the above table it is noted that there are not significant statistical differences due to the variable of the educational directorate, and therefore, it could be said that there are no differences between the four directorates (Qasabat Ma'an, Shobak, Badia and Petra) in applying the five components of the diagnostic evaluation method in the copied dictation lessons.

\subsection{Discussion of the Results}

To answer the first question, table 1, in comparing the benchmark (3) it is clear that the benchmark is high, which show that the teachers applying the method of diagnostic evaluation.

To examine these means, as per T-test, table 2 shows that the teachers who teach the copied dictation by applying the method of diagnostic evaluation, have the main components (appendix 2) and apply it while teaching dictation. This proves that the teachers apply what they learned from the training courses they received while in-service.

On the other hand, this shows that the teachers define the weakness and strength points during the diagnostic evaluation and they detect and treat the weakness while dictating the text on the students. Moreover, those teachers follow the steps in sequence and get away of working randomly while planning to the class situations and deciding the expected objectives. Teacher also provided the students with training by using the black board or any other suitable means; they distribute the students according to their power in writing dictation; they treat and remedy the weaknesses and help the students avoid committing mistakes, and if necessary, the teacher provides training and informs them about their weaknesses and strengths. In addition, the teacher inform the administration to treat weaknesses, communicates with the parents to inform them about the writing levels of their children, how to handle this issue, detects the situations and makes a follow up for the improvement, while adopting the formative evaluation (continuously) as well as the diagnostic evaluation which shall be followed while teaching. By this, we have answered the first question of the study.

As for the second result, table 3 shows clear differences between the means of the participants according to the educational directorates (Qasaba, Shobak, Badia and Petra).

It is noted that the evaluation in the four directorates was less than the benchmark. Regarding the other components, they were slightly higher than the benchmark (3). To examined the significance of these differences, the uni-vairance analysis was used (table 4 ) which shows not significant statistical differences due to the variable of the directorate.

Accordingly, there are no differences among the four directorates in applying the five components of the diagnostic evaluation in the dictation lessons.

This result can be explained that the Ministry of Education, since starting the educational development in 1987 introduced new and developed methods by foreigner experts who had long experience in the educational development. Supervisors received training and were sent in training courses, gained experiences and provided training to the teachers on such methods, including the diagnostic evaluation. This method is concerned with all student levels, where it defines the weak ones, while not neglecting the good students, with a critical follow up by the school and the specialist educational supervisor.

It is worth mentioning that the teachers who teach the first grades (from grade one-three) with experience and hold a B.A. in the specialty of (class room teacher), apply all what they learned, use all available means as well as the diagnostic evaluation methods in sequence steps, followed by the specialist supervisors, treat the defect step-by-step, and this method increases activity, cooperation and motivates those teachers to gain more learning.

The dictation copies that were chosen for this group were taken from previous, handle objective educational issues and appropriate with their levels and capacities, not to forget the linguistic dictionary of those students. Accordingly, all results were close among the four educational directorates while applying the diagnostic evaluation method, which defines defects first-by-first, and treat it prior to becoming so complex, with the cooperation of all stakeholders of the learning-teaching process. With this, we have answered the second question.

The results of this study were consistent with Mohammed (2003); Mukhtar (1994); Sa'eed (1983) and Marion (1997). However, the results of this study were not consistent with Hussein (2000), which showed that the traditional group was better than the group that received instruction through the diagnostic evaluation method. Despite such fact, this result did not affect the importance of this method that enhances the role of students in the learning process, with focus on the individualized learning and diagnosis of defects first-by-first and provides the suitable treatment, which is the main call of modern education. 


\section{Recommendations}

In light of the results, the researcher would propose the following recommendations:

1-Increase the training courses for the first grade teachers on using the diagnostic evaluation method, prior and while in-service.

2-Expand instruction using the diagnostic evaluation method so as to include the middle and higher primary grades.

3-More focus on the first primary grade students, then they are at the beginning of the learning process.

4-More focus on the listening and testing dictation and teaching them to the higher grades, using the components of the diagnostic evaluation method, in order to uncover weaknesses and make remedy and strengths and enhance them.

5-Conduct more studies on the other grades, to generalize the benefit of this method.

6-Provide the Arabic curriculum specialists with the results of this study to provide more focus in the teachers' guide on how to teach this group using the diagnostic evaluation method.

\section{References}

Al-Bajjeh, A. H. (1994). Teaching children the reading and writing skills (vol. 1). Dar Al-Fikr Publishing, Printing and Distribution.

ALfairzabadi, M. B. Y. (1994). In Yousif Al-Sheeh Al-Biqa'i, \& Beirut, Dar Al-Fikr (Eds.), Al-Muheet dictionary.

Al Hashimi, A. (2009). analysis of the content of the Arabic language curriculum-An applied theoretical perspective (vol. 1). Dar Al-Safa Publishing \& Distribution, Amman, Jordan.

Al-Ja'afreh, A. (2011). Curriculum of Arabic language and teaching methods between theory and practice (vol. 1). Arab community library for publishing and distribution.

Al-Kholi, M. A. (2000). Methods of teaching Arabic language, Dar Al-Falah Publishing and Distribution. Swaileh, Jordan.

Al-Kilani, A. Z. (1993). Measurement and evaluation in teaching and learning (vol. 1). Publications of Open Jerusalem University, Amman

Badawi, A. (1980). Dictionary of educational terms, Dar Al-Fikr Al-Arabi, Egyptian Est. for Publishing, printing and distribution.

Devire, M. (1997). Arepoton visit to Jordan. Constancy Diagnostic (15-27, November, p. 2).

Hasan, A. A. (2000). The efficiency of teaching by using the diagnostic evaluation method for Arabic material in the primary stage in Kerak governorate. Unpublished $\mathrm{PhD}$, Jordan.

Ibrahim, M. (1989). Al-waseet dictionary (vol. 1). Dar Al-Da'wa Publishing and Distribution, Istanbul, Turkey.

Jabir, W. (2002). Teaching of Arabic language, theory concepts and practical applications (vol. 1). Dar Al-Fikr Publishing, Printing and Distribution, Amman.

Manthour, A. B., \& Al-Ifriqi, J. E. (1968). Lisan Al-Arab. Dar Al-Malayeen for Science- Beirut.

Margaret, R. K., \& Mary, A. S. (1991). Maximizing student performance in summary writing Managing cognitive load. TESOL Quarterly, 25(1), 101-116.

Miqbel, M. S. (1997). A training matrix on the diagnostic evaluation method. Ministry of Education, Amman, Jordan.

Mokhtar, I. B. (1995). University of Pittsburgh (1994). Development and validation of multi component diagnostic test of arithmetic World problem solving ability for 6-9 grade student Malaysia. Dissertation Abstracts international, 55 .

Safasfeh, A. (2004). Methods of teaching Arabic language. Yazeed Publication Library, Kerak, Jordan.

Saud, O. A. (1983). The Effect of using Diagnostic prescriptive Teaching on Achievement in scients. Doctoral Dissertation, Dissertation Abstract international.

Tarawneh, M. A. N. (2003). Efficiency of teaching Arabic language using the diagnostic evaluation method for the primary stage in Kerak. 
Thondike. (1961). Measuremet and education in psychology Education. New York.

\section{Appendix A}

The degree of applying the components of the diagnostic evaluation while teaching the copied dictation

\begin{tabular}{|c|c|c|c|c|c|}
\hline & Toobig(5) & Big (4) & Medium (3) & Little (2) & Too little (1) \\
\hline $\begin{array}{l}\text { First: planning: } \\
\text { - Deciding the educational } \\
\text { objectives of the dictation } \\
\text { lesson. } \\
\text { - Dividing the main objectives } \\
\text { into sub-objectives. } \\
\text { - Deciding the outputs of } \\
\text { learning that should be } \\
\text { evaluated. } \\
\text { - Deciding the prior } \\
\text { requirements of the dictation } \\
\text { lesson. } \\
\text { - Puts suitable criteria for the } \\
\text { students' success or failure in } \\
\text { their performance. }\end{array}$ & & & & & \\
\hline $\begin{array}{l}\text { Second: learning: } \\
\text { - considers the logical } \\
\text { sequence in presenting } \\
\text { dictation. } \\
\text { - Employs appropriate } \\
\text { technology to present the } \\
\text { dictation lesson. } \\
\text { - Uses suitable teaching aids. } \\
\text { - End the class in a way that is } \\
\text { consistent with this group. } \\
\text { - Provides assistance for the } \\
\text { students who face specific } \\
\text { difficulties. }\end{array}$ & & & & & \\
\hline $\begin{array}{l}\text { Third: detecting the results: } \\
\text { - Detects the mistakes in } \\
\text { which the student fall. } \\
\text { - Detects the students' } \\
\text { achievements. } \\
\text { - Detects students } \\
\text { improvement in writing. } \\
\text { - Decides weakness and } \\
\text { strengths of each student. } \\
\text { - Proposes good decisions for } \\
\text { the student learning. }\end{array}$ & & & & & \\
\hline $\begin{array}{l}\text { Forth: distributing the } \\
\text { student results to the } \\
\text { stakeholders: } \\
\text { - Informing the students about }\end{array}$ & & & & & \\
\hline
\end{tabular}




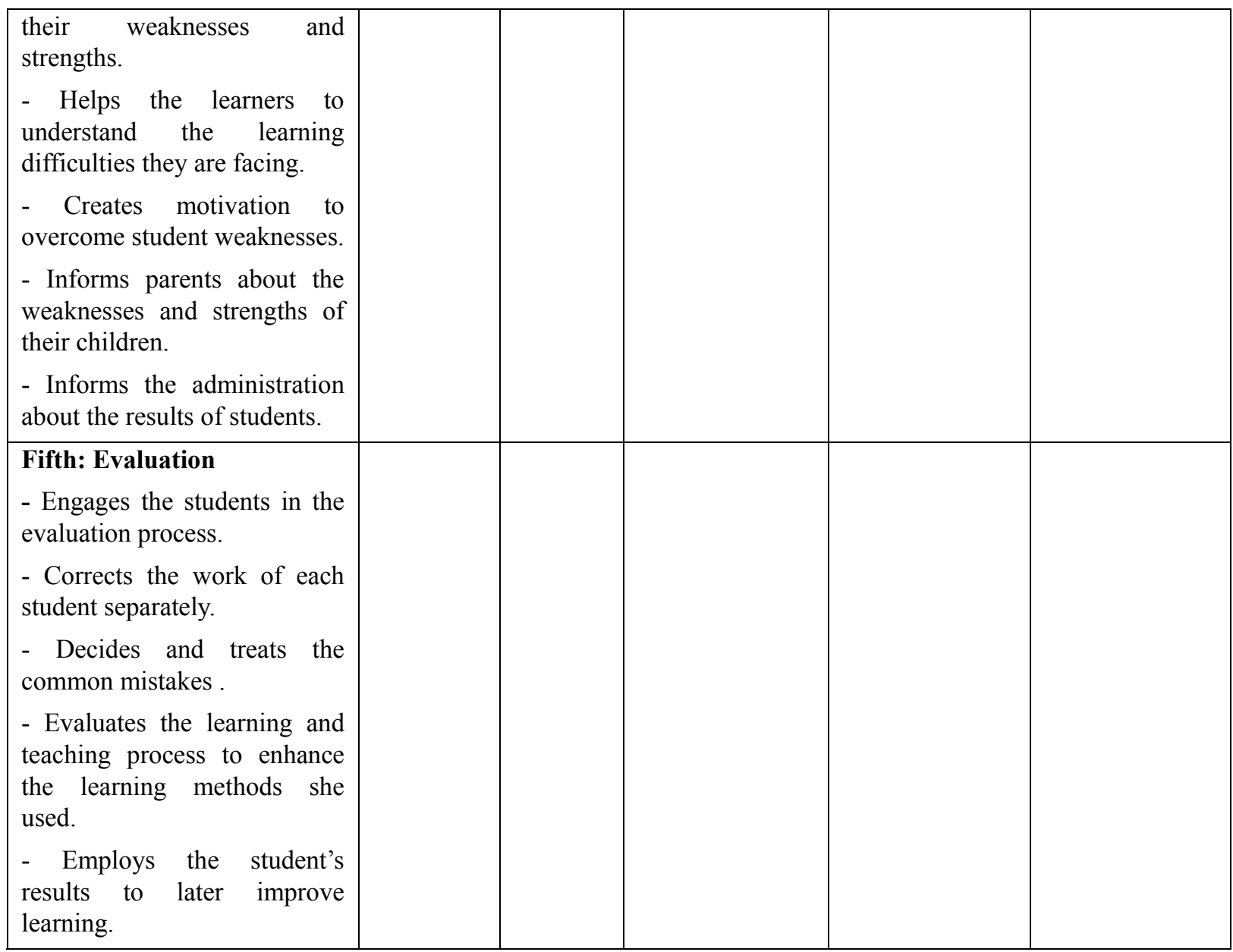

\section{Copyrights}

Copyright for this article is retained by the author(s), with first publication rights granted to the journal.

This is an open-access article distributed under the terms and conditions of the Creative Commons Attribution license (http://creativecommons.org/licenses/by/3.0/). 